\section{Distribution pattern of orchids in Uttarakhand, Western Himalayas, India}

\author{
Jeewan Singh Jalal \\ Botanical Survey of India, Western \\ Regional Centre, Maharashtra, India
}

\begin{abstract}
Orchids are widely distributed in tropics, subtropics and temperate regions. Within the tropics, orchids form an important feature of the vegetation, chiefly as epiphytes. India's epiphytic orchid is to be found primarily in the Eastern Himalayas and Western Ghats, while the terrestrial species flourishes in the Western Himalayas. In the state of Uttarakhand, India, orchid distribution is not homogeneous. Orchids are typically concentrated along the riverine areas and in pockets of moist forests where there is suitable habitat for their growth, development and regeneration. The purpose of this study was to provide a general review of the distribution of orchid species (epiphytic and terrestrial) in Uttarakhand. A total of 240 species (of which 10 are endemic) belonging to 73 genera were recorded. The largest number of orchid species (terrestrial and epiphytic) were encountered in the sub-tropical zone $(<1500 \mathrm{~m})$. Terrestrial orchids were distributed throughout the altitudinal gradient, but the largest number of species occurred in two ecotones between high and low altitude forests $(1500-2000 \mathrm{~m}$ and $3000-3500 \mathrm{~m})$. Twenty-one species were restricted to a particular habitat.
\end{abstract}

\section{Introduction}

Orchidaceae is one of the largest families of flowering plants in the world. ${ }^{1}$ Many of the estimated 20,000-30,000 species are locally distributed and are generally rare. ${ }^{2,3}$ Orchids are concentrated in three areas, notably tropical America, Indo-Malayan and the Eastern Himalayas. About $73 \%$ of species are epiphytes, ${ }^{4}$ and these make a significant contribution to the epiphytic plant communities in the tropical forests. Orchids are very widely distributed but their largest diversity occurs in the tropics. ${ }^{4}$ Orchid species are not to be found in a few isolated islands and Antarctica.

India's orchids are found from sea level to the snow covered alpine regions but their numbers vary in different regions due to the prevailing climatic conditions. In the state of Uttarakhand, the distribution of the orchids is not homogeneous. ${ }^{5}$ The largest number of orchid species is concentrated in Eastern India and the Western Ghats. The epiphytic species are found at $1800 \mathrm{~m}$ above sea level and frequency decreases the higher the altitude. Epiphytic orchids mainly occur in the Eastern Himalayas and the Western Ghats. The majority of the non-epiphytic or terrestrial orchid species grow in the Western Himalayas and at higher altitudes in the Eastern Himalayas. The purpose of this study was to provide a general review of the distribution of orchid species (epiphytic and terrestrial) in Uttarakhand, India.

\section{Materials and Methods}

\section{Study area}

The state of Uttarakhand lies between $28^{\circ} 5324$ to $31^{\circ} 27^{\prime} 50 \mathrm{~N}$ and $77^{\circ} 3427$ to $81^{\circ} 0222 \mathrm{E}$ (Figure 1) making up an area of $53,483 \mathrm{~km}^{2}$. This area accounts for approximately $1.62 \%$ of the total area of the country. Elevation ranges from $300 \mathrm{~m}$ to over $7817 \mathrm{~m}$ above sea level. The climate of Uttarakhand varies from sub-tropical to alpine. It is relatively cool and humid compared to the rest of the Western Himalayas. Except for inner dry ranges, much of the state receives high precipitation during the months of July to September and heavy snow during the months of November to January at higher altitudes (>3000 $\mathrm{m}$ a.s.l.). The total forest area of the state is approximately $45 \%$ of the total geographical area. ${ }^{6}$ The vegetation cover types were classified according to the dominant forest species by Champion and Seth and include: ${ }^{7}$ tropical moist deciduous forests, subtropical pine forest, sub-tropical dry evergreen forest, West Himalayan temperate broad leaf forest, West Himalayan conifer forest, subalpine forest and alpine scrub. In addition, a large number of secondary formations, such as temperate grassy slopes and special habitats, e.g. riverine forests, are found in the state, which is rich in orchids.

\section{Data collection}

Data were collected from various sources: specimens deposited in various herbaria, the Botanical Survey of India, the Northern Circle, the Forest Research Institute, the Kumaon University Nainital and the HNB Garhwal University, Srinagar, and taxonomic literature and field surveys from 2002 to $2009 .{ }^{8-10}$ All the herbarium specimens have been deposited at the Wildlife Institute of India Herbarium. Various eco-climatic zones, ${ }^{11}$ tropical $(<500$ $\mathrm{m})$, sub-tropical (500-1500 m), warm temperate $(1500-2500 \mathrm{~m})$, cool temperate $(2500-3000$ $\mathrm{m})$, sub-alpine $(3000-3500 \mathrm{~m})$ and alpine
Correspondence: Jeewan Singh Jalal, Botanical Survey of India, Western Regional Centre, 7 Koregaon Road, Pune- 411001, Maharashtra, India.

E-mail: jeewansinghjalal@rediffmail.com

Key words: altitudinal gradient, orchids, ecotone, Uttarakhand, sub-tropical.

Acknowledgments: the author is thankful to the Director of the Botanical Survey of India for encouragement and facilities. Thanks to Dr. J. Jayanthi for her much needed support and encouragement. Thanks to the Ministry of the Environment and Forests, Government of India for the financial support to carry out this work.

Conflict of interests: the author reports no conflict of interests.

Received for publication: 16 May 2012.

Revision received: 25 June 2012.

Accepted for publication: 25 June 2012.

This work is licensed under a Creative Commons Attribution NonCommercial 3.0 License (CC BYNC 3.0).

CC Copyright J. Singh Jalal 2012

Licensee PAGEPress srl, Italy

International Journal of Plant Biology 2012; 3:e5 doi:10.4081/pb.2012.e5

$(>3500 \mathrm{~m})$ in the state were covered. Information on behavior, habitats and distributional range were recorded. For the sake of convenience, the altitudinal zones have been further categorized into eight belts at $500 \mathrm{~m}$ intervals between 300 and $4800 \mathrm{~m}$ (the higher limit of the orchids in Uttarakhand is $4000 \mathrm{~m}$ ), starting from below $500 \mathrm{~m}$ up to over $3500 \mathrm{~m}$.

\section{Results}

The present paper records 240 species from 73 genera. These species are 130 terrestrial, 11 saprophytic and 99 epiphytic. In total, the number of terrestrial orchids was higher than that of the epiphytic. The most dominant genera were genus Habenaria and Dendrobium (15 spp. each), Bulbophyllum (12 spp.), Liparis and Oberonia (10 spp. each), Eulophia (10 spp.), Eria (9 spp.), Calanthe, Cymbidium and Herminium (8 spp. each). The distribution of orchids in different eco-climatic zones of the state is shown in Figure 2. Epiphytic orchids are mainly distributed only up to an altitude of $2500 \mathrm{~m}$. The largest numbers of orchid species were recorded in the sub-tropical zone where the riverine habitats provide all the most suitable conditions for their growth and development. Due to the high moisture to be found in 
the riverine areas, some orchids grow both on tree trucks and on rock surfaces, e.g. Coelogyne cristata Lindl., Coelogyne ovalis Lindl., Luisia zelyanica Lindl., Oberonia acaulis Griff., Pholidota imbricata Lindl., Pholidota articulata Lindl. and Thunia alba (Lindl.) Rchb.f..

The eastern part of the state, i.e. the Kumaun region, is more mesic than the Garhwal region and, therefore, supports a larger number of orchids. The most eastern district of Uttarakhand, i.e. Pithoragarh, has approximately $50 \%$ of the orchids reported in the state. The Lower Gori Valley in Pithoragarh, the Eastern Ramganga Valley (Pithoragarh district), the Asiganga Valley (Uttarkashi district) and the Mandal Valley (Chamoli district) are just some of the richest localities in the state for the number of orchids found.

The overall pattern of orchid species according to altitude is shown in Figure 3. There is a significant increasing trend in total species richness from $500 \mathrm{~m}$ to $2000 \mathrm{~m}$. From $2000 \mathrm{~m}$ to over $3500 \mathrm{~m}$ there is a clear decrease. Thus, orchid species richness in Uttarakhand peaks at lower altitudes from 1500-2000 m. This is found for approximately $45 \%$ of the total species of orchids found in the study area. The pattern of orchid species richness according to altitudinal zones shows a hump-shaped distribution pattern, with high species richness in the middle altitudinal zone between $1500 \mathrm{~m}$ and $2000 \mathrm{~m}$. According to Gerytnes and Vettas, about half of the published studies showed a mid-elevation peak in plant species richness. This zone has much higher rainfall than other higher altitudinal zones. Due to high moisture levels, the largest numbers of epiphytic orchids are found in this zone. The riverine pocket of this zone provides all the most suitable conditions for orchid growth and development. There was a major decrease in epiphytic species richness above $2000 \mathrm{~m}$ that could be due to the low moisture level and low number of epiphytic species found there. Terrestrial orchids have also shown a significantly increasing trend. Terrestrial species richness is very low at below 500 $\mathrm{m}$ and over $3500 \mathrm{~m}$. The low altitudinal zone receives less rainfall and temperatures exceed $45^{\circ} \mathrm{C}$ in many places. At the highest altitudes, temperatures fall to $-20^{\circ} \mathrm{C}$ with permanent snow cover. Neither of these factors favor orchid growth and development.

\section{Discussion}

Altitude plays a significant role in determining the forest types, communities and species distribution in mountainous regions, and also represents a complex gradient along which many environmental variables change concomitantly. ${ }^{12}$ Several studies have found a decreasing trend in species richness with
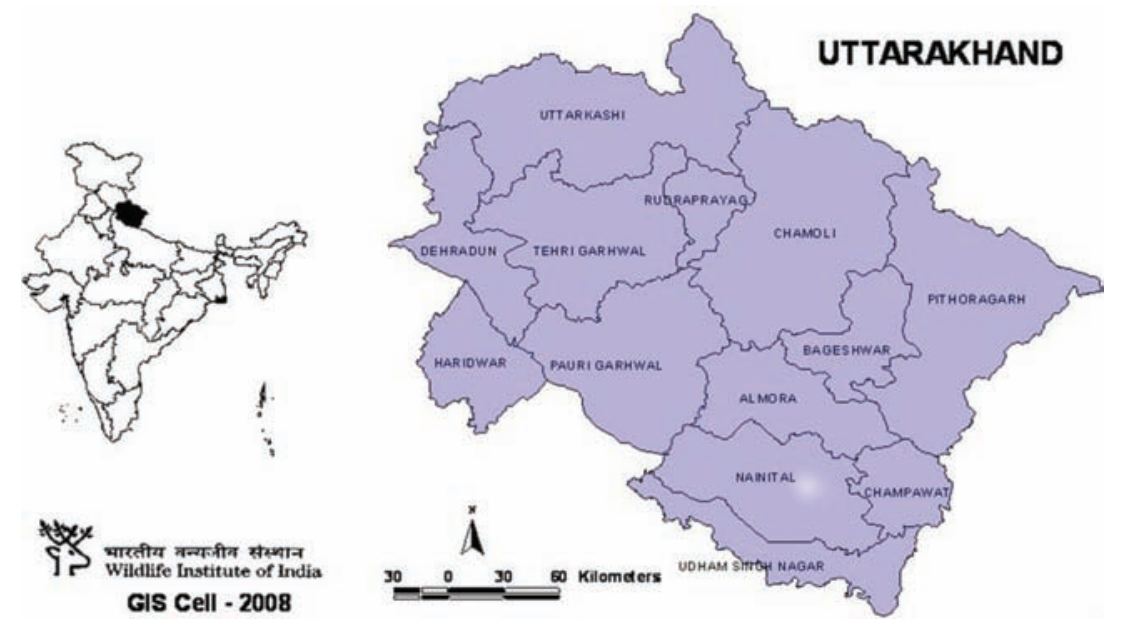

Figure 1. Map of the study area.

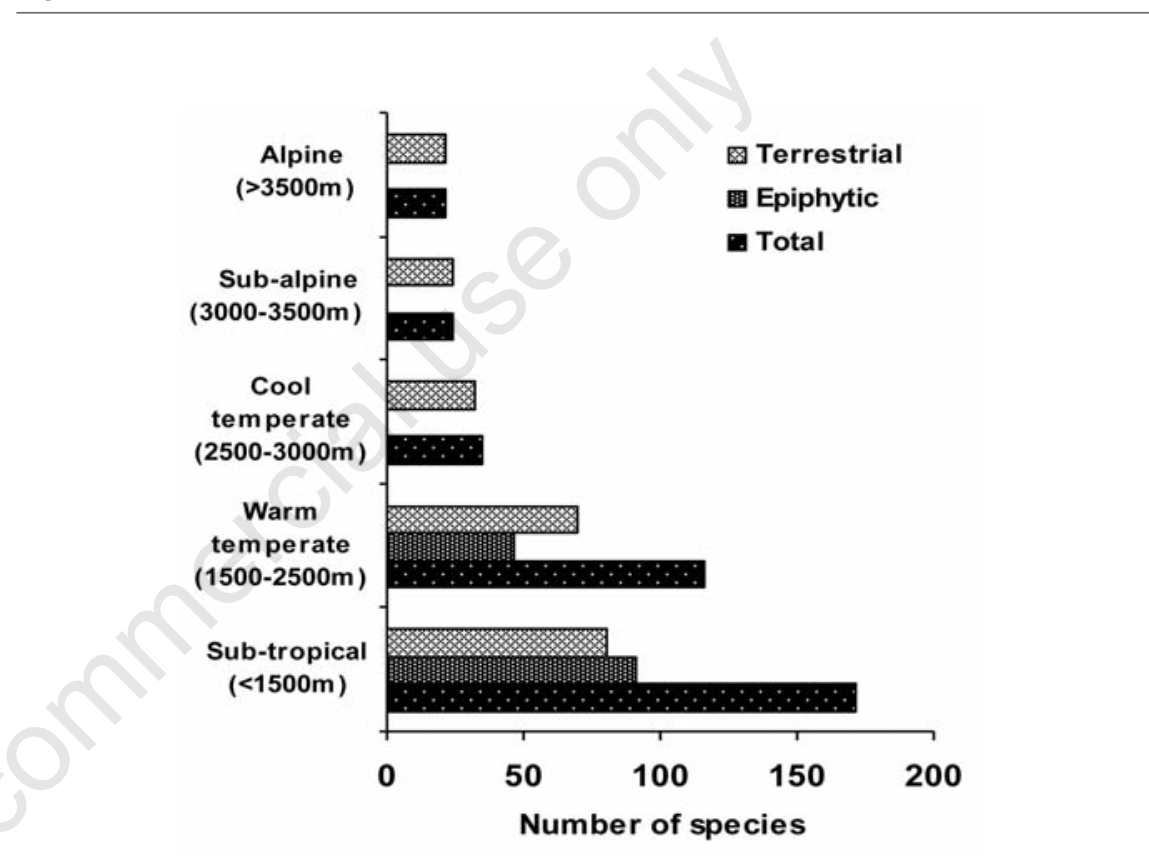

Figure 2. Distribution of orchids in the various eco-climatic zones.

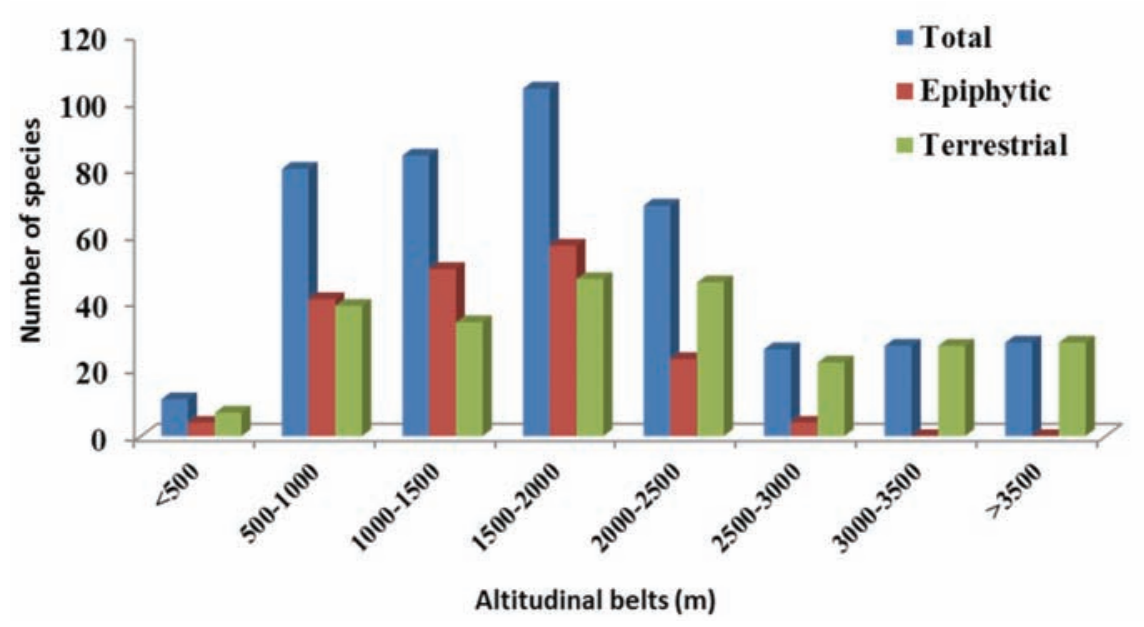

Figure 3. Distribution of orchids in different altitudinal belts. 
increasing elevation, ${ }^{13-15}$ whereas others have found a hump-shaped relationship between species richness and elevation. ${ }^{16,17}$ The present data show that as altitude increases the orchid species richness decreases. The high temperatures and low rainfall of the low altitudinal zone $(<500 \mathrm{~m})$ harm orchid growth because soil moisture and humidity are essential factors for this and orchid species richness is, therefore, low. The terrestrial orchids are distributed throughout the altitudinal gradient, but their maximum representation is between two altitudinal ecotones: 1500-2000 m and $3000-3500 \mathrm{~m}$. In fact, these zones represent an ecotone between high and low altitude forests, such as chir pine and banj oak forests at lower altitudes, mixed-conifer and broadleaved evergreen forest at higher altitudes, and several other forest types, such as silver fir (Abies pindrow), tilonj oak (Quercus floribunda), horse chestnut (Aesculus indica), maple (Acer caesium, Acer cappadocicum) and alder (Alnus nepalensis) forests.

Climatic variables influence species richness along elevational gradients for all kinds of living organisms. The climatic factors that vary with elevation include temperature, length of growing season, humidity, air pressure, nutrient availability, ultraviolet radiation and rainfall, ${ }^{18}$ which can all have an influence on the distribution of species along the gradient. ${ }^{19}$ Epiphytic orchids show their highest concentration between $500 \mathrm{~m}$ and $2500 \mathrm{~m}$. The humid and moist valleys and riverine forests provide the most congenial habitats for the growth and development of a number of epiphytic orchids in this zone. For the epiphytic orchids, availability of moisture and the host species are the crucial factors. Moisture levels (humidity) appear to be more important for the growth of epiphytic orchids and the availability of higher moisture levels is the main factor in their growth. Many shrubs, woody climber (Bauchinia vahlii) and palm (Phoenex humilis) also support the epiphytic orchids. Interestingly, due to high moisture in many riverine areas, a dendroid cacti, Euphorbia roylena, serves as host species for epiphytic orchids.

\section{References}

1. Atwood JT. The size of the Orchidaceae and the systematic distribution of epiphytic orchids. Selbyana 1986;9:171-86.

2. Tremblay RL. Distribution and dispersion patterns of individuals in nine species of Lepanthes (Orchidaceae). Biotropica 1997;29:38-45.

3. Benavides AM, Duque AJ, Duivenvoorden JF, et al. A first quantitative census of vascular epiphytes in rain forests of Colombian Amazonia. Biodiversity and Conservation 2005;14:739-58.

4. Dressler RL. The orchids. Natural history and classification. Cambridge: Harvard University Press; 1981.

5. Jalal JS. Systematics, phytogeography and habitat ecology of orchids of Uttarahcnal. Nainital, Uttarakhand: Kumaun University; 2005.

6. Forest survey of India Dehradun. State of forest report 2001. Available from: www. fsi.in

7. Champion HG, Seth SK. A revised survey of forest types of India. Delhi: Government of India; 1968.
8. Deva S, Naithani HB. The orchid flora of north-west Himalaya. New Delhi, 1986.

9. Duthie JF. The orchids of the north-western Himalaya. Annals of Royal Botanic Garden Calcutta 1906;9:81-211.

10. Pangtey YPS, Samant SS, Rawat GS. Orchids of Kumaon Himalaya. Dehradun: Bishan Singh Mahendra Pal Singh; 1991.

11. Singh JS, Singh SP. Forest of Himalaya: structure, function and impact of man. Nainital, India: Gyonoday Prakashan Publisher; 1992.

12. Whittaker RH. Gradient analysis of vegetation. Biologic Rev 1967;42:207-64.

13. Stevens GC. The elevational gradient in altitudinal range, an extension of Rapoport's latitudinal rule to altitude. Am Nat 1992;140:893-911.

14. Wolda H. Altitude habitat and tropical insect diversity. Biological Journal of the Linnean Society 1987;30:313-23.

15. Yoda K. A preliminary survey of the forest vegetation of eastern Nepal. Journal of Art and Science. Chiba University National Science series 1967;5:99-140.

16. Grytnes JA, Vetaas OR. Species richness and altitude, a comparison between simulation models and interpolated plant species richness along the Himalayan altitudinal gradient, Nepal. Am Nat 2002;159: 294-304.

17. Rahbek C. The elevational gradient of species richness, a uniform pattern? Ecography 1995;18:200-5.

18. Funnell D, Parish R. Mountain environments and communities. London, New York: Routledge physical environment series; 2001.

19. Korner C. Alpine plant life. Berlin: Springer Verlag; 1999. 